\title{
Health, Illness, Men and Masculinities (HIMM): a theoretical framework for understanding men and their health
}

\section{Keywords}

Men's health

Masculinity

Gender

Social

determinants of

health
Joan Evans

Division of Medical

Education, Dalhousie

University, Halifax, Nova

Scotia, Canada B3H 4H7

Blye Frank

Dalhousie University,

Halifax, Nova Scotia,

Canada

John L. Oliffe

University of British

Columbia, Canada

David Gregory

University of Lethbridge,

Canada

E-mail:

joan.evans@dal.ca

Online 26 January 2011

\section{Joan Evans, Blye Frank, John L. Oliffe and David Gregory}

\section{Abstract}

Gender, the complex of social relations and practices attached to biological sex, is one of the most important socio-cultural factors influencing health and health-related behavior. Although a large body of health research suggests that men with similar social disadvantages as women experience poorer health outcomes in relation to disability, chronic illness, injury rates and mortality, men's health is rarely deconstructed through the lens of gender. The purpose of this article is to increase understanding of the ways in which masculinities intersect with other social determinants of health creating health disparities among men, and to provide direction for masculine affirming health interventions aimed specifically at men. With the goal of promoting the health of men and decreasing health disparities, the authors have developed, within the Canadian context, an innovative theoretical framework for men's health, Health, Illness, Men and Masculinities (HIMM), based on the influence of masculinity throughout the lifecourse. We discuss three main phases of men's lifecourse showing how masculinity intersects with other social determinants of health differently during youth, middle-age and the older years. The HIMM Framework points to the need for research and theory development that moves us beyond a limited focus on any one individual man to consider men's health and illness practices in the larger social context within which masculinity is defined and produced. It can thus advance men's health research and theory development, and provide direction for policy, education, health care delivery and health promotion initiatives aimed specifically at men in many locales, contexts and countries. ๑ 2010 WPMH GmbH. Published by Elsevier Ireland Ltd.

\section{Background}

Gender, the complex of social relations and practices attached to biological sex, is one of the most important socio-cultural factors influencing health and health-related behavior [1], but rarely is men's health deconstructed through the lens of gender [2,3]. A large body of health research suggests that men with similar social disadvantages as women experience poorer health outcomes in relation to mortality, disability, chronic illness, and injury rates [4]. For example, using age-standardized frequencies to control for the greater life expectancy of women, data from Statistics Canada in 2005 showed that men are $39 \%$ more likely to die from diabetes, $84 \%$ from arterial diseases, and $78 \%$ from heart disease [5]. Men of all ages experience a significantly higher mortality rate from all kinds of cancer (using age-standardization and excluding sexspecific cancers), and this higher rate of death in men becomes even more pronounced for men over age 65 [6]. Men's rate of lost years of life is twice that of women, primarily due to men's higher mortality from heart disease, 
suicide and motor vehicle accidents [7,8]. Despite gender being widely acknowledged as a determinant of health, this kind of research fails to explain the mechanisms by which gender influences men's health. For instance, although substantially higher rates of lung and oesophageal cancer in men have been linked to smoking patterns and explained by factors such as lifestyle, genetics, health knowledge, uptake of screening, and help-seeking behavior [6], the connections between men's everyday smoking practices and masculinity have rarely been explored $[9,10]$. Schofield et al. [4] reveal how the dominant discourse on men's health can oversimplify by generalizing men's poor health outcomes as a "combination of social disadvantage and an ill-defined state defined by such phrases as 'being a man'." Furthermore, most of the men's health literature is based on sex differences and quantitative rates of difference in illness outcomes for men as compared to women [4]. This limitation points to the need for research that is capable of producing gender-sensitive analyses of men's lives and masculinities in relation to health and illness.

\section{Men, masculinities and gender ideology}

Connell [11] defines masculinity as a social construction dependent on a specific historical time, culture and locale. Such a definition captures the complexity of men's lives, which "like all lives, are always individual, always particular and inexhaustibly various" [12], and moves us away from the essentialist notion that a relatively stable or unitary masculine essence exists that defines men and differentiates them from a feminine essence that defines women [13]. Masculinity is also defined in relational terms, as that which is not feminine $[14,15]$. In addition, within any given society there can exist a hierarchy of masculinities with an idealized version being dominant or hegemonic [15]. In Western culture, contemporary hegemonic masculinity is associated with being White, heterosexual and middleclass, and possessing stereotypical masculine traits of assertiveness, dominance, control, physical strength and emotional restraint. As a result, many men experience subordination and marginalization as a consequence of not measuring up to the ideal standard against which all men are judged. Indeed, Connell suggests that only a small percentage of men actually can and do measure up to a hegemonic version of masculinity [16]. This has significance in relation to men's health practicesparticularly for boys and men who jeopardize their health striving to demonstrate this ideal.

Although some men achieve power and prestige in patriarchal societies, in general, men are more constrained than women by gender ideologies, receiving greater scrutiny and stigma should they deviate toward un-masculine or feminine practices, and fail to embody or reject idealized productions of masculinity [14]. Maintaining hegemonic masculine identities can be challenging for men given that identity is performatively constituted [17] and manliness measured by the continual proving of manhood [18]. In other words, men are only as masculine as their last demonstration of masculinity [19]. Therefore, men participate in 'risky' practices that cause them hardship and pain, illustrating the way in which gender operates within an informal but powerful ideology of gender difference [18].

\section{Masculinity as a determinant of health}

Canadian health researchers have identified gender as an important social determinant of health [9,20-22]. More recently, researchers have begun to investigate how sociological theories of gender may influence men and women's health within the social context of their everyday lives [10,23-25]. In 2000, the World Health Organization (WHO) acknowledged the need to pay greater attention to the shorter life expectancy of men and identified a lack of understanding of the role of 'masculinity' in shaping men's expectations and behaviours as a primary causative factor for the health disparity between men and women [26].

Health promoting and coping behaviors are aligned with constructs related to traditional femininity (caring) and masculinity (stoicism), and health practices and behaviours may be understood as activities by which we construct our understanding of self and gender [27]. Increasingly, literature reveals that being a woman is the strongest predictor of preventative and health-promotion behavior $[28,29]$. 
Women employ more effective coping strategies, are more likely to seek social support, and are more effective in the provision of support than men [28]. Because health-promoting behaviors are linked with femininity, and risk-taking health behaviors are linked with masculinity, men's alignment with masculine ideals is theorized to contribute to the health disparity between men and women. Courtenay [30] illustrates the risk associated with masculinity by suggesting that men who fall short of achieving idealized masculinity feel stigmatized or marginalized and respond through socioculturally-defined compensating behaviors that place them at high risk of injury and illness. He adds that men will often prefer to face risk and physical discomfort rather than be associated with traits perceived to be feminine, such as vulnerability, dependence and weakness [28]. Furthermore, because illness is associated with weakness and vulnerability, we understand men's perception of illness and reluctance to seek treatment as the avoidance of femininity or perceived emasculating behaviors. For example, African-Canadian men in Nova Scotia avoided digital rectal exams for prostate cancer screening because of the association between the penetration of men's bodies, homosexuality and compromised masculinity [22]. Prostate cancer generates intense emotions connected to a sense of loss in masculinity resulting from treatment side effects such as impotence and incontinence [31]. As suggested by Oberst \& James [32] and Oliffe [33], sexual dysfunction can have a more significant impact on men than the disease itself. In fact, men will avoid accessing cancer care for as long as possible, because not knowing is deemed preferable to knowing and undergoing emasculating treatments [22].

The relationship of masculinity to health is reciprocal in nature and most evident in situations when an illness or disease is specifically identified as 'feminine.' Although only $1 \%$ of men make up breast cancer cases, men diagnosed with this 'feminine' cancer suffer a fatality rate double that of women (31-33\%). Men reported feeling "shocked and foolish" for having been diagnosed with a "female cancer" [34], their threatened masculine identities the primary cause for delaying diagnosis and/or treatment [35]. Reinforcing the feminine identification of breast cancer, the Canadian Can- cer Society and the American Cancer Society focus on women (fund raisers, pink ribbon campaign, breast self exam, etc) and exclude men as potential victims of breast cancer. The message that men can develop breast cancer remains silent.

The tendency for many men to engage in high risk practices (e.g., excessive use of alcohol; high speed driving etc), avoid preventative care, delay treatment, and ignore health information and physician recommendations can be interpreted as practices of masculinity and, in turn, contribute to poor health outcomes for men $[1,36,37]$. That said, in most health analyses that have conceptualized 'men as gendered', little attention has been given to the ordinary, everyday practices that constitute masculinity $[12,38-40]$ and their effect on individuals and diverse cohorts of men, as well as the broader collective of men in Canadian society.

\section{Multiple masculinities and men's health}

The concept of multiple masculinities, hegemonic, complicit, subordinate and marginalized forms [15], reflects the social diversity of men associated with age, race, ethnicity, culture, class, sexuality, ability, etc. Men who belong to subcultures categorized by marginalized masculinities based on race, ethnicity or sexual orientation experience poorer health outcomes than other groups of men. Gay men (marginalized in Connell's schema), suffer the consequences of homophobia through violence, social isolation, high-levels of suicide, self-harm, and unsafe sexual practices [41].

Likewise, First Nations (Aboriginal) men living off-reserve experience poorer health than the general population in all parts of Canada, urban or rural [42], and registered First Nations men die an average 8.1 years younger than men in the general Canadian population [43]. A review of the social determinants of health for African-American men in the USA identified racism, lower socio-economic class, and incarceration as key determinants of health status [44]. The health of African-Canadian men is poorly understood; however, USA statistics indicate that the life expectancy of African-American men is 5.5 years less than that of White men. Black men also lead White men in death rates from stroke, homicide, diabetes, 
and HIV [45]. Furthermore, research with African-Canadian men in Nova Scotia communities concluded that prostate cancer may have greater impact on Black men than White men because, culturally, sexual virility and prowess were perceived to be the primary avenues available for Black men to affirm masculinity in the face of their limited access to other resources such as high status employment [22]. In this instance, gender was inextricably linked to other health determinants such as socio-economic status, employment, education, and rural location.

Such findings show how health determinants within specific subgroups are not generalizable to all men; conversely, some groups of men may not experience specific health factors that have been deemed characteristic of all men [4]. By taking into account the social diversity across men, the 'traditional' men's health discourse is challenged to acknowledge that men are not one overarching or homogenous category [4]. In addition to multiple masculinities across the category 'men', what it means to be a man and practices of masculinity change in response to locale, life events and aging across the lifespan. For men, age has a significant impact on health in light of agerelated constructions of masculinity. Men define and redefine masculinity based on life events and the social context of their experiences throughout the lifecourse $[1,3,20]$.

The focus of this article is to increase our understanding of the ways in which masculinities intersect with other social determinants of health creating health disparities among men, and to provide direction for masculine affirming health interventions aimed specifically at men. With the goal of promoting the health of men and decreasing health disparities, in what follows we describe an innovative, Canadian based, theoretical framework for men's health based on the influence of masculinity throughout phases of the lifecourse.

\section{Exploring the intersections of Health, Illness, Men and Masculinities (HIMM) across the lifecourse}

The HIMM Framework (developed by J. Evans, B. Frank, J. L. Oliffe, D. Gregory, D. Divine, D. LeDuc and M. Numer) points to the need for research and theory development that moves beyond a limited focus on any one individual man to consider men's health and illness-related practices in the larger social context within which masculinities are defined and produced. Such understanding would inform health promotion, policy, education and healthcare delivery initiatives aimed specifically at men if improved health outcomes for men are to be realized. Fig. 1, the HIMM Framework, shows how masculinity and men's health are interconnected.

Specifically, the HIMM Framework depicts masculinities as a social determinant of health that intersects other determinants such as socio-economic status, race, ethnicity, sexuality, ability, geography, community, education, and employment. Because masculinities are socially constructed within particular social, political and historical contexts, the definitions and practices of masculinity vary among societies and men. Adding to the complexity of men's health, practices of masculinity also vary across the lifecourse of any one man's life in response to aging, life events and history.

\section{Boys and masculinity in youth}

The health outcomes of young men in Canada offer an alarming snapshot: young men are three times more likely to die from accidental death than young women; four times more likely to die from suicide; and half as likely to seek out health care services [46]. For example, in Nova Scotia, male youth (12-24 years of age) constitute over $50 \%$ of the youth population; however, health care contacts for male youth are almost half that of female youth [47]. When boys do access health care, they are twice as likely to visit emergency rooms for injury/poisoning, and are three times more likely to die from accidental injury, including motor vehicle accidents [47].

Most boys are socialized to embody hegemonic masculinity and 'take it like a man' at an early age, and are discouraged from showing feelings of vulnerability or weakness [48]. The implications of this are problematic because the social expectation of toughness and independence, as suggested by Good et al. [49], lead to the suppression of emotion, social isolation, and resistance to asking for help. This complex intertwining of health and gender becomes 


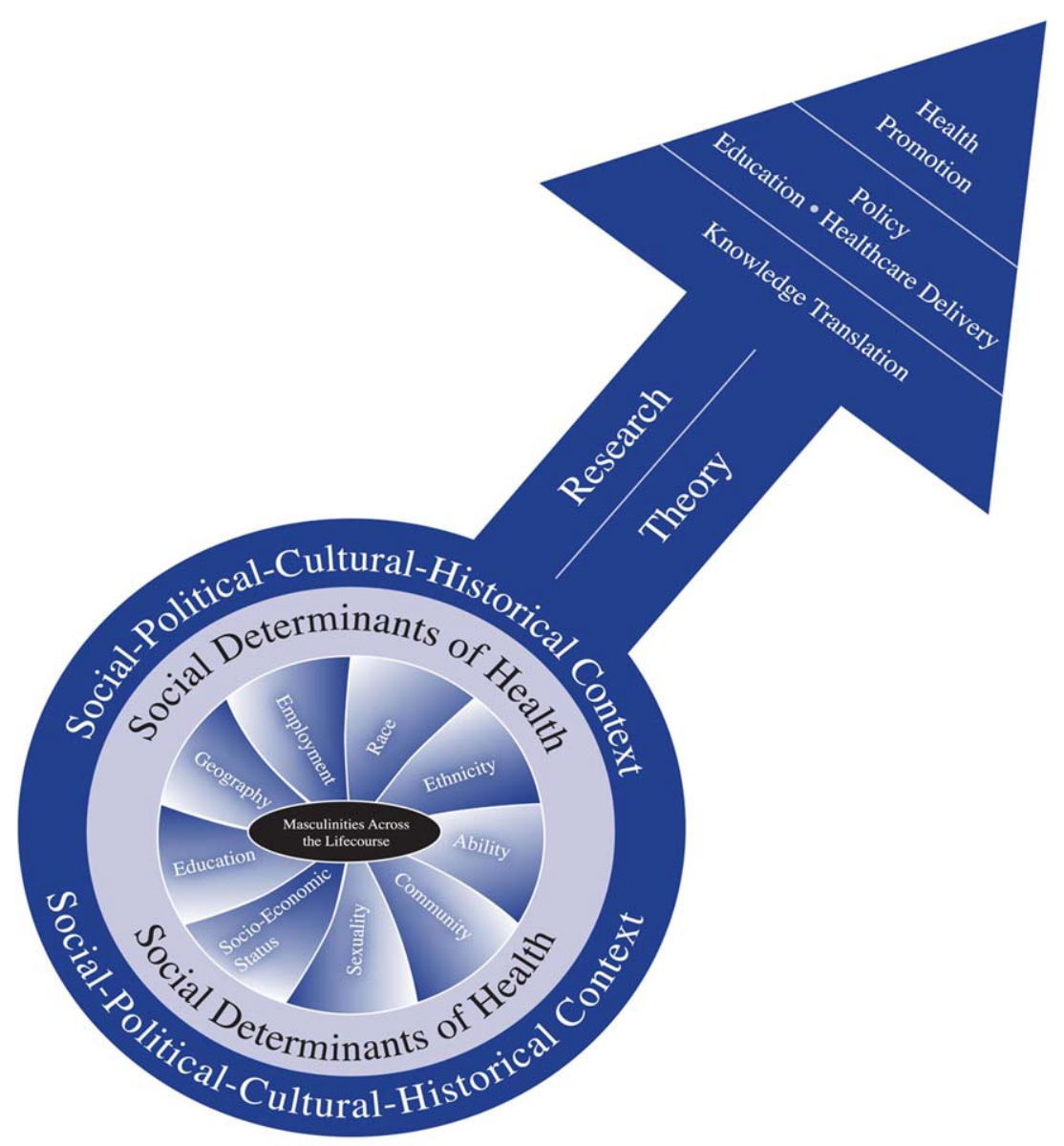

Fig. 1 The HIMM (Health, Illness, Men and Masculinities) Framework.

evident within families of origin at the level of local communities, and impacts boys at a young age.

For boys and young men, physical risk is naturalized, promoted, and celebrated [50], their bodies are agents of gendered social practice through demonstrations of aggression, strength, and risk taking [51]. In Canada, boys and men are more active in sports than girls and women, the gap being most evident during the teenage years for ages $15-18$ (80\% boys vs. 55\% girls) [52]. Not surprisingly, sport injury reflects the gendering of sport in the form of a greater number of injuries, and more severe injuries, incurred by boys and men who dominate high risk, physical contact sports $[53,54]$. For example, snowmobile accidents amid an absence of legislated and enforced safety precautions (i.e., helmets, speed restrictions) render boys and youths susceptible to head injuries, multi-trauma, and disabilities. Snowmobiling all too often connects risk tak- ing behavior, masculinity and machines. More than half of snowmobile collisions involve child drivers, and $65 \%$ of these are boys around 12 years of age [55], a majority of whom are not wearing helmets [56].

Consistent with historical trends, the reported rate for Chlamydia infection in young adults is almost double for women compared to men. With age however, this ratio changes and in the 40 and older age groups, Chlamydia infection rates are higher in men [57]. Despite health promotion efforts, rates of sexually transmitted infections (STIs) have increased across all age groups with the greatest increase of Chlamydia infection being in men aged 2024 years. For example, in British Columbia (BC), Canada, Chlamydia rates for young men doubled between 1997 and 2006; and gonorrhoea rates amongst $\mathrm{BC}$ men increased by over $100 \%$ during the same time period [25]. Young men's hyper-sexualization of the clinical exam for STIs, and the tendency for men to prefer to 
self-monitor symptoms pose barriers to helpseeking [25]. In addition to masculine identities influencing health practices in this instance, we find structural forces at play in the health system which could be modified (e.g. urine analysis for some STIs). Sexual health issues become entwined with gender constructs at multiple levels when we consider that the Canadian health care system monitors girls' and young women's bodies to a far greater extent than those of young men.

\section{Men and masculinity in the middle years}

Midlife men have unique considerations in both the construction of their masculinities and how their practices of masculinity intersect with other determinants of health to influence their health and health care practices. During this phase of life, men construct their masculinity in relation to the physicality of their work and/or the level of income their labor produces. Thus, for men, work defines their status in the masculine hierarchy and has significance as a site for the social production of masculinity [41]. Work that involves physical labor often calls for men to demonstrate their masculinity through stoicism and the denial of bodily pain that results from physical labor. In Canada, $90 \%$ of the victims of work-related fatalities are men. An important observation is that men, rather than women, generally perform high risk, physical labor thus increasing their risk of injury. Williams [58] suggests that masculinity itself is a contributing factor. For men in white-collar jobs, the hard-working, achievement-oriented Type A personality is associated with stressrelated health conditions such as coronary artery disease. In the discourse on men's health, the 'repackaging' of the white-collar businessman into a healthier model of success is evident in the concept of the 'hardy man'-a personality style characterized by commitment rather than alienation, control rather than powerlessness, and challenge rather than threat [59]. Riska [60] argues that the notion of hardiness, that is being in control and work committed, reflects the idealized or hegemonic version of masculinity. Here, the powerful, cool-headed, and successful man manages stress with masculine stoicism and strength.
As men approach mid-life many experience this time as a turning point, a time of reassessment and taking stock of their lives and achievements [61]. Lough \& Sanford [62] suggest that between the ages of 35 and 50 , men experience a psychological and spiritual crisis manifested by symptoms such as depression, boredom, fatigue, irritability, physical complaints and excessive drinking. Despite active disease or conditions, men may deny their symptoms as a means of maintaining allegiance to hegemonic masculinity. This is illustrated in research conducted by the Canadian Mental Health Association [63], in which men described having experienced symptoms of depression without acknowledging being depressed. It is hypothesized that the failure of men to recognize mental health issues may contribute to the higher rates of suicide among men [23]. The most significant statistic suggesting men's vulnerability regarding mental illness is that four out of every five suicides in Canada are carried out by men [62]. Middle-aged men often suffer silently with depression, and screening tools and diagnostic criteria that are biased towards capturing traditional 'feminine' signs of depression, including internal self-judgment and external expression of sadness, rather than the anger, emotional numbing, substance abuse, and impoverished relationships that typically emerge in and around men's depression, are also implicated [64].

\section{Men and masculinity in later life}

Older men also have unique considerations in both the construction of their masculinities and how practices of masculinity influence their health and illness practices. While the developmental challenge of midlife men has received significant attention in the psychology literature, the lives of older men remain mostly unexplored, "so much so that older men have been categorized as 'invisible men in contemporary society' [65]". As men age and illness becomes more frequent, the inability to sustain hegemonic masculine ideals by keeping the body muscular, strong and resilient may threaten men's self-perceptions of their masculinity [66], and men are faced with the challenge of redefining themselves within an idealized, masculine culture [67]. As men's bodies change with age, their location in the 
gender hierarchy is altered [61]. While some men may find dignity and new opportunities in aging, Pease [61] notes that others experience a deepening sense of crisis accompanied by a growing awareness of their own mortality. Transitions from career and work life to retirement can be stressful, especially amid times of economic downturn and/or when unplanned or enforced $[68,69]$. In addition to unemployment [70], older men's masculine ideals can be further eroded by diseases of older age including prostate cancer [33] and heart disease [60].

The extent to which men's aging represents deterioration and loss versus liberation from rigid gender expectations is not known; however, the aging process and accompanying propensity to develop illness and experience reduced physical capacity in later life adds another layer of complexity to the provision of health care for older men.

\section{Conclusions}

Health behaviour within the context of gender is a powerful and influential health determinant for individuals. Given that social constructions of masculinity shape men's perceptions of health and illness and their subsequent health care practices, hegemonic masculinity and traditional beliefs about manhood are the strongest predictors of individual risk behaviour over the lifecourse [28]. The HIMM Framework explores masculinities as a determinant of health and health disparity between men and women and among men as a diverse social group. By taking a developmental perspective of men's health over the lifecourse, we have identified additional health disparities among men that remain largely invisible and unexplored, and shown how they intersect with health disparities based on differences such as age, employment, education, socioeconomic status, ethnicity and sexuality.

There is also a need to move from description toward interventions in ways that mobilize what we have learned about masculinities and men's health and illness practices. Furthermore, men-centered interventions should also be targeted to specific sub-groups, while being responsive to men's particular lifecourse health issues. Examples of this approach include the Families Controlling and Eliminating Tobacco program that developed The Right Time, The Right
Reasons print-based tobacco reduction intervention for dads who smoke [71]. The content was developed from the perspectives of dads who smoke and, rather than a 'how-to-quit' guide, the focus is to encourage dads who smoke to contemplate tobacco reduction (the brochure is downloadable at www.facet.ubc.ca). In terms of older men's mental health, the Australian Men's Sheds initiative [72,73] and the UK's men in sheds program [74] have successfully attracted men to workshop-type spaces in community settings to provide opportunities for regular hands-on activity for groups deliberately and mainly comprising men. Many of the attendees are older men facing issues associated with significant change, such as aging, retirement, isolation, unemployment, disability and separation, and they report mateship and a sense of belonging as key benefits of their participation in the positive and therapeutic informal activities of the groups [72,73]. In all of these programs, masculine ideals have informed both the design and delivery of men-centred interventions.

To date, the majority of research conducted in the area of men's health and masculinities has taken place in the United States and Australia $[1,34,66]$. The HIMM theoretical framework builds on this work and adds knowledge specific to the health of Canadian men. Having said that, because masculinity is a social construct that varies within and across cultures, the HIMM Framework has utility across locales and cultures. It can, thus, advance men's health research and related theory development, as well as provide direction for policy, education, health care delivery and health promotion initiatives aimed at men in many locales, contexts and countries.

\section{Acknowledgements}

This research and article was made possible by a Nova Scotia Health Research Foundation Collaborative Health Research Project Grant and a Capacity Team Development Grant as well as a Canadian Institutes of Health Research Meetings, Planning and Dissemination Grant. Career support for J.L. Oliffe is provided by a Canadian Institutes of Health Research new investigator and a Michael Smith Foundation for Health Research scholar award. Many thanks to Mary T. Kelly for her assistance with this article. 
References

[1] Courtenay W. Constructions of masculinity and their influence on men's well-being: a theory of gender and health. Soc Sci Med 2000;50:1385-401.

[2] Kimmel M, Messner M. Introduction. In: Kimmel M, Messner M, editors. Men's lives. 2nd edn. Toronto: Maxwell MacMillan Canada; 1992. p. 1-11.

[3] Lohan M. How might we understand men's health better? Integrating explanations from critical studies on men and inequalities in health. Soc Sci Med 2007;65(3):493-504.

[4] Schofield T, Connell R, Walker L, Wood J, Butland D. Understanding men's health and illness: a gender-relations approach to policy, research, and practice. J Am Coll Health 2000;48:247-56.

[5] Statistics Canada. Age-standardized mortality rates by selected causes, by sex: 20032007. Available from: http://www40. statcan.gc.ca/l01/cst01/health30c-eng.htm [accessed 26. 04.10].

[6] National Cancer Intelligence Network, Cancer Research UK, Leeds Metropolitan University and Men's Health Forum. The excess burden of cancer in men in the UK; 2009. Available from: http://info.cancerresearchuk. org/cancerstats/inequalities/index.htm [accessed 24.05.10].

[7] Bilsker D, Goldenberg L, Davison J. A roadmap to men's health: current status, research, policy and practice. Men's health initiative of British Columbia, UBC and SFU Centre for applied research in mental health and addiction. Vancouver; 2010. Available from: http://www.aboutmen.ca/helpfulstuff/mens-health-report [accessed 23.04.10].

[8] Gregory D, Evans J, Frank B, Kellett P. Men's Health: the need for change. Well-Spring (Alberta Centre for Active Living) 2008; 19(1):1-4.

[9] Bottorff JL, Oliffe JL, Kalaw C, Carey J, Mroz L. Men's constructions of smoking in the context of women's tobacco reduction during pregnancy. Soc Sci Med 2006;62(12): 3096-108

[10] Oliffe JL, Bottorff JL, Johnson JL, Kelly MT, LeBeau K. Fathers: locating smoking and masculinity in the postpartum. Qual Health Res 2010;20:330-9.

[11] Connell RW. Gender and power: society, the person and sexual politics. Stanford, CA: Stanford University Press; 1987.

[12] Frank B. The 'new men's studies' and feminism: promise or danger? In: Haddad T, editor. Men and masculinities. A critical anthology. Toronto: Canadian Scholarly Press; 1993. p. 333-43.

[13] Petersen A. Unmasking the masculine. 'Men' and 'Identity' in a skeptical age. London: Sage; 1998.
[14] Messner M. The limits of The Male Sex Role: an analysis of the men's liberation and men's rights movements' discourse. Gender Soc 1998;12(3):255-76.

[15] Connell RW. Masculinities. Sydney: Allen \& Unwin; 1995.

[16] Connell RW. The big picture: masculinities in recent world history. Theory Soc 1993;22 597-623.

[17] Berger $M$, Wallis $B$, Watson $S$. Introduction. In: Berger $M$, Wallis $B$, Watson $S$, editors. Constituting masculinities. New York: Routledge; 1995. p. 1-7

[18] Connell RW. Teaching the boys: new research on masculinity, and gender strategies for schools. Teach Coll Rec 1996;98(2) 206-35.

[19] Kimmel S. Manhood in America: a cultural history. New York: Free Press; 1996.

[20] Oliffe JL. Health behaviors, prostate cancer and masculinities: a life course perspective. Men Masc 2009;11(3):346-66.

[21] Raphael D. Introduction to the social determinants of health. In: Raphael $D$, editor. Social determinants of health: Canadian perspectives. 2nd edn. Toronto: Canadian Scholars' Press; 2008. p. 2-19.

[22] Evans J, Butler L, Etowa J, Crawley I, Rayson $D$, Bell D. Gendered and cultured relations: exploring African Nova Scotians' perceptions and experiences of breast and prostate cancer. Res Theory Nurs Pract 2005;19(3) 257-73.

[23] Oliffe JL, Ogrodniczuk JS, Bottorff JL, Johnson JL, Hoyak K. "You feel like you can't live anymore": suicide from the perspectives of men who experience depression. Soc Sci Med 2010 [Epub May 24]

[24] Oliffe JL, Grewal S, Bottorff JL, Dhesi J, Kang HBK, Ward A, et al. Masculinities, diet and senior Punjabi Sikh immigrant men: food for Western thought? Sociol Health III 2010;32(5):761-76

[25] Shoveller J, Knight RE, Johnson JL, Oliffe JL, Goldenberg S. "Not the swab": young men's experiences of STI testing. Sociol Health III 2010;32(1):57-73.

[26] World Health Organization. What about the boys? A literature review on the health and development of adolescent boys. Geneva: WHO; 2000, Available from: http://whqlibdoc.who.int/hq/2000/WHO_FCH_CAH_ 00.7.pdf [accessed 23.04.10].

[27] Saltonstall R. Healthy bodies, social bodies: men's and women's concepts and practices of health in everyday life. Soc Sci Med 1993;36:7-14.

[28] Courtenay W. Engendered health: a social constructionist examination of men's health beliefs and behaviors. Psychol Men Masc 2000;1(1):4-15.

[29] Ratner PA, Bottorff JL, Johnson JL, Hayduk $L A$. The interaction effects of gender within the health promotion model. Res Nursing Health 1994;17:341-50.

[30] Courtenay W. Key determinants of the health and the well-being of men and boys. Int J Men's Health 2003;2(1): $1-30$.

[31] Kelly D. Changed men: the embodied impact of prostate cancer. Qual Health Res 2009;19(2):151-64.

[32] Oberst M, James R. Going home: patient and spousal adjustment following cancer surgery. Top Clin Nurs 1995;7(1): 46-57.

[33] Oliffe JL. Positioning prostate cancer as the problematic third testicle. In: Broom A, Tovey $\mathrm{P}$, editors. Men's health: body, identity and social context. London, UK: John Wiley \& Sons Ltd; 2009. p. 33-62.

[34] Naymark P. Male breast cancer: incompatible and incomparable. J Men's Health Gend 2006;3(2):160-5.

[35] Pituskin E, Williams B, Au H, Martin-McDonald $K$. Experiences of men with breast cancer: a qualitative study. J Men's Health Gend 2007;4(1):44-51.

[36] Gibson M, Denner B. Men's health report 2000. The MAN model. Pathways to men's health. Daylesford, Victoria, Australia: Centre for Advancement of Men's Health; 2000. Available from: http://nrha.ruralhealth. org.au/conferences/docs/PAPERS/5_man. pdf [accessed 29.04.10].

[37] Taylor C, Stewart A, Parker R. 'Machismo' as a barrier to health promotion in Australian males. In: Laws T, editor. Promoting men's health - an essential book for nurses. Ascot Vale: Ausmed Publications; 1998.

[38] Frank B. Hegemonic heterosexual masculinity. Stud Polit Econ 1987;24:159-70.

[39] Frank B. Everyday masculinities. Unpublished doctoral dissertation. Dalhousie University, Halifax, NS; 1990.

[40] Frank B. Masculinity meets postmodernism: theorizing the 'Man Made' man. Can Folklore Can 1997;19(1):15-33.

[41] Lee C, Owens R. Issues for a psychology of men's health. J Health Psychol 2002;7(3): 209-17.

[42] Tjepkema M. Statistics Canada. The health of the off-reserve aboriginal population. Supplement to health reports, vol. 13. Ottawa: Statistics Canada. 2002 Available from: http://www.statcan.gc.ca/bsolc/ olc-cel/olc-cel? lang=eng $\&$ catno $=82-003$ X20021016323 [accessed 5.05.10].

[43] Health Canada, First nations comparable health indicators. Ottowa: Health Canada. 2005, Available from: http://www.hc-sc. gc.ca/fniah-spnia/diseases-maladies/200501_health-sante_indicat-eng.php [accessed 23.04.10].

[44] Xanthos C, Treadwell HM, Holden KB. Social determinants of health among African- 
American men. J Men's Health 2010;7(1): 11-9.

[45] Centers for Disease Control and Prevention. Leading causes of death in males: United States; 2004. Atlanta, GA: CDC. Available from: http://www.cdc.gov/men/lcod/2004/ index.htm [accessed 23.04.10].

[46] Public Health Agency of Canada (PHAC). Street youth in Canada: findings from enhanced surveillance of Canadian street youth from 1999-2003. Ottawa: PHAC; 2006, Available from: http://www.phacaspc.gc.ca/std-mts/reports_06/pdf/street_ youth_e.pdf [accessed 27.04.10]

[47] The NSYOUTH Research Team. Youth in Nova Scotia. A ten year audit of healthcare utilization. DRAFT phase 1 Report 2006-0925. Halifax, NS: The Population Health Research Unit, Dalhousie University; 2006.

[48] Addis M, Mahalik J. Men, masculinity, and the contexts of help seeking. Am Psychol 2003;58(1):5-14.

[49] Good GE, Dell DM, Mintz LB. Male role and gender role conflict: relations to help seeking in men. J Counsel Psychol 1989;36:295300.

[50] Young K, White P. Researching sports injury: reconstructing dangerous masculinities. In: McKay J, Messner M, Sabo D, editors. Masculinities, gender relations, and sport. Thousand Oaks, CA: Sage; 2000 . p. 108-26.

[51] Kimmel M, Messner M, editors. Men's lives. 3rd edn. Toronto: Allyn and Bacon; 1998.

[52] Sport Canada. Sport participation in Canada - 1998 report. Ottawa: Minister of Public Works and Government Services Canada; 2000. Available from: http://www. pch.gc.ca/pgm/sc/info-fact/1998-psc-spc/ index-eng.cfm [accessed 5.05.10].

[53] Emery C, Meeuwisse W, McAllister J. Survery of sport participation and sport injury in
Calgary and area high schools. Clin J Sport Med 2006;16:20-6.

[54] Kujala U, Taimela S, Antii-Poika I, Prava S, Tuominen R, Myllellen P. Acute injuries in soccer, ice hockey, volleyball, basketball, judo, and karate: an analysis of national registry data. BMJ 1995;311:1465-8.

[55] Decou JM, Fagerman LE, Ropele D, Uitvlugt ND, Schlatter MG, Connors RH. Snowmobile injuries and fatalities in children. $J$ Pediatr Surg 2003;38(5):784-7.

[56] Nayci A, Stavlo PL, Zarrough AE, Zietlow SP, Moir CR, Rodeberg DA. Snowmobile injuries in children and adolescents. Mayo Clin Proc 2006;81(1):39-44.

[57] Public Health Agency of Canada (PHAC). Report on sexually transmitted infections in Canada. Ottawa: PHAC; 2008. Available from: http://198.103.98.78/std-mts/report/ sti-its2008/03-eng.php

[58] Williams D. The health of men: structured inequalities and opportunities. Am J Public Health 2003;93(5):724-31.

[59] Maddi SR, Kobasa SC. The hardy executive: health under stress. Homewood, IL: Dow Jones-Irwin; 1984.

[60] Riska E. From Type A man to the hardy man: masculinity and health. Sociol Health III 2002;24(3):347-58.

[61] Pease B. Men and gender relations. Melbourne: Tertiary Press; 2002.

[62] Lough G, Sanford JA. What men are like: the psychology of men, for men and the women who live with them. New York: Paulist Press International; 1988.

[63] Canadian Mental Health Association. Men's mental health: a silent crisis. Ottowa: CMHA; 2004, Available from: http://www. cmha.ca/bins/content_page. asp?cid=3-726 \&lang=1 [accessed 23.04.10].

[64] Oliffe JL, Phillips MJ. Men, depression and masculinities: a review and recommen- dations. J Men's Health 2008;5:194202.

[65] Fleming AA. Older men in contemporary discourses on ageing: absent bodies and invisible lives. Nur Inq 1998;6:3-8.

[66] Oliffe JL. Embodied masculinity and androgen deprivation therapy. Sociol Health III 2006;28(4):410-32.

[67] Arber S, Davidson K, Ginn J. Gender and ageing. Changing roles and relationships. Philadelphia: Open University Press; 2003.

[68] Marshall V, Clarke PJ, Ballantyne PJ. Instability in the retirement transition: effects on health and well-being in a Canadian study. Res Aging 2001;23:379-409.

[69] Soares J, Macassa G, Grossi G, Viitasara E. Psychosocial correlates of hopelessness among men. Cogn Behav Ther 2008; 37(1):50-61.

[70] Calasanti T, King N. Firming the floppy penis. Age, class, and gender relations in the lives of old men. Men Masc 2005;8(1):3-23.

[71] Families Controlling and Eliminating Tobacco (FACAET). The right time, the right reasons. Kelowna, BC: FACET; 2010, Available from: http://www.facet.ubc.ca/PressRelease.aspx.

[72] Williamson T. Grumpy old men? Older men's mental health and emotional wellbeing In: Conrad D, White A, editors. Promoting men's mental health. Abingdon, UK: Radcliffe; 2010. p. 111-24.

[73] Golding B, Foley A, Brown M. The international potential for men's shed-based learning. AdLib J Cont Lib Adult Educ 2007;34:913.

[74] Golding B, Brown M, Foley A, Harvey J, Gleeson L. Men's sheds in Australia: learning through community contexts. Research report. Adelaide: NCVER; 2007. Available from: http://www.ncver.edu.au/publications/1780.html [accessed 17.08.10]. 